\title{
Comparison of head size and bite force in two sister species of parrotbills
}

\author{
Xiaodong Rao ${ }^{1}$, Canchao Yang ${ }^{1 *}$, Laikun Ma' ${ }^{1}$, Jianwei Zhang ${ }^{1}$, Wei Liang ${ }^{1 *}$ (I) and Anders Pape Møller ${ }^{2}$
}

\begin{abstract}
Background: Brain size is associated with morphological evolution and behavioral flexibility because animals with large brain size tend to utilize new resources and colonize novel environments more successfully. Therefore, animals with larger brain size should possess larger distribution ranges. Brain size is strongly positively correlated with head size in birds, but also with prey size and vocalizations, because individuals with large heads eat large food items and produce high frequency calls.
\end{abstract}

Methods: To test if there exists an association between head morphology and bite performance, we compared head size and bite force in two sympatric sister species of parrotbills, Ashy-throated Parrotbill (Paradoxornis alphonsianus) and Vinous-throated Parrotbill (P. webbianus), which both originated from the Himalayan area, but differ significantly in their distribution ranges.

Results: In Guizhou, southwestern China, the Ashy-throated Parrotbill with a restricted distribution range had smaller heads whilst the Vinous-throated Parrotbill with a large distribution range had larger heads. However, there were no differences in head size between Ashy-throated Parrotbills and allopatric populations of Vinous-throated Parrotbills (Jiangxi and Hebei). Furthermore, the tendency of variation in bite force was opposite to that in head size with populations with larger head size having weaker bite force.

Conclusions: We showed that there are no differences in head size between the Ashy-throated Parrotbill and allopatric populations of Vinous-throated Parrotbill, which provides evidence for the hypothesis that differences in head size in the Guizhou populations of two sister species are probably the result of local adaptation rather than species-specific. Our study has implications for avian dispersal and adaption related to head size such as diet ecology and vocalizations.

Keywords: Behavioral flexibility, Distribution range, Paradoxornis alphonsianus, Paradoxornis webbianus, Sister species

\section{Background}

The evolution of the nervous system, especially the brain, is a key for animals to perceive and respond to the environment in which they live. Brain size has been found to be associated with morphological evolution. Large brains are associated with increased behavioral flexibility thus enabling animals to successfully cope with novel environmental challenges, and large brains are beneficial for individuals under new selective regimes (Wyles et al. 1983; Sol and Lefebvre 2000; Sol et al. 2002; Healy

\footnotetext{
*Correspondence: ccyang@hainnu.edu.cn; liangwei@hainnu.edu.cn ${ }^{1}$ Ministry of Education Key Laboratory for Ecology of Tropical Islands, College of Life Sciences, Hainan Normal University, Haikou 571158, China Full list of author information is available at the end of the article
}

and Rowe 2007). Because large brain size favors individuals when establishing in novel environments, it also increases the opportunities for allopatric speciation (Sol and Price 2008). Brain size was related to foraging innovations among species (Lefebvre et al. 1997). For example, brain size as a reflection of cognitive skills accounted for the ability to cope with novel habitats (Sol et al. 2005). In addition, the northern distribution limits of birds are governed by the relative size of the hippocampus (Garamszegi and Lucas 2005). In birds, brain size is strongly positively correlated with head size (Møller 2010), but also with prey size and vocalizations, because individuals with large heads eat large food items and produce high frequency calls (Podos 2001; Podos et al. 2004). 
Bite force is another important ecological trait of animals that may be tightly linked to both type and magnitude of the ecological challenges such as food acquisition, mate choice through effects on vocalizations, competition for access to mates and physical defense against predators (Anderson et al. 2008). A recent study revealed fast-evolving ecomorphological variation among populations of Lizard (Podarcis bocagei), where a direct association existed between head morphology and bite performance (Gomes et al. 2018). Therefore, both brain size and bite force are important traits for successful dispersal and colonization of novel environments.

Here we hypothesize that bird species with larger distribution ranges may have larger head size, and we test this by comparing head size in two sister species of parrotbills (Fig. 1) that differ considerably in distribution range (Fig. 2). These two sister species of parrotbills, Ashy-throated Parrotbill (Paradoxornis alphonsianus) and Vinous-throated Parrotbill (P. webbianus), both originate from the Himalayan area and have long been considered two subspecies of the same species (Delacour 1946). Recent studies also indicated that these two parrotbill species may be conspecific, and that they have diverged ca. 856,000 years ago, although substantial gene flow occurs after presumed secondary contact ca. 290,000 years ago (Yeung et al. 2011; Shaner et al. 2015). Although these two parrotbills can be regarded either as sister species or distinct subspecies, their distribution ranges are significantly different with the Ashy-throated

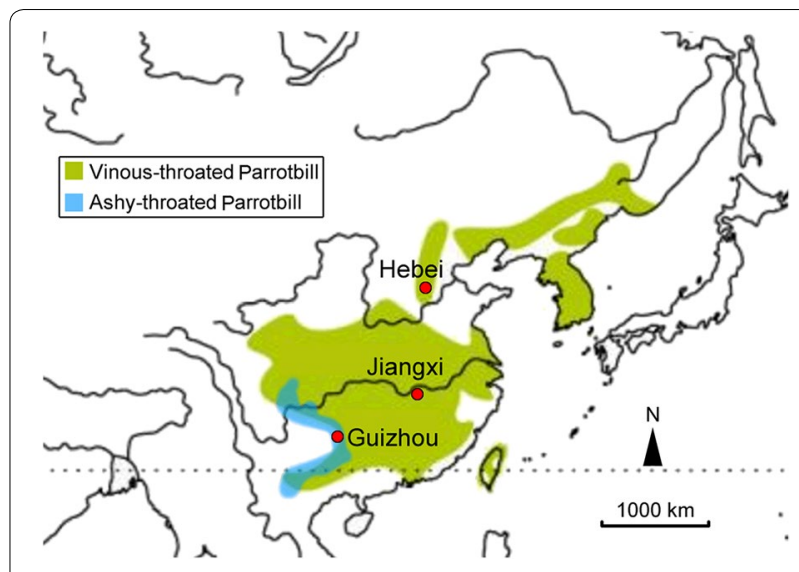

Fig. 2 The distribution ranges and sampling sites of two sister species of parrotbills in this study. For Vinous-throated Parrotbills, three geographic populations were sampled, including Guizhou, Jiangxi and Hebei whilst for Ashy-throated Parrotbills the Guizhou population was sampled

Parrotbill limited to the Himalayan area while the Vinous-throated Parrotbill has dispersed to northern and eastern China where it occupies a much larger area. Thus a comparison of morphology of these two species constitutes a unique opportunity for this study. We predicted that the Vinous-throated Parrotbill possesses a larger head size than does the Ashy-throated Parrotbill. Furthermore, bill size and bite force were also compared between these populations.
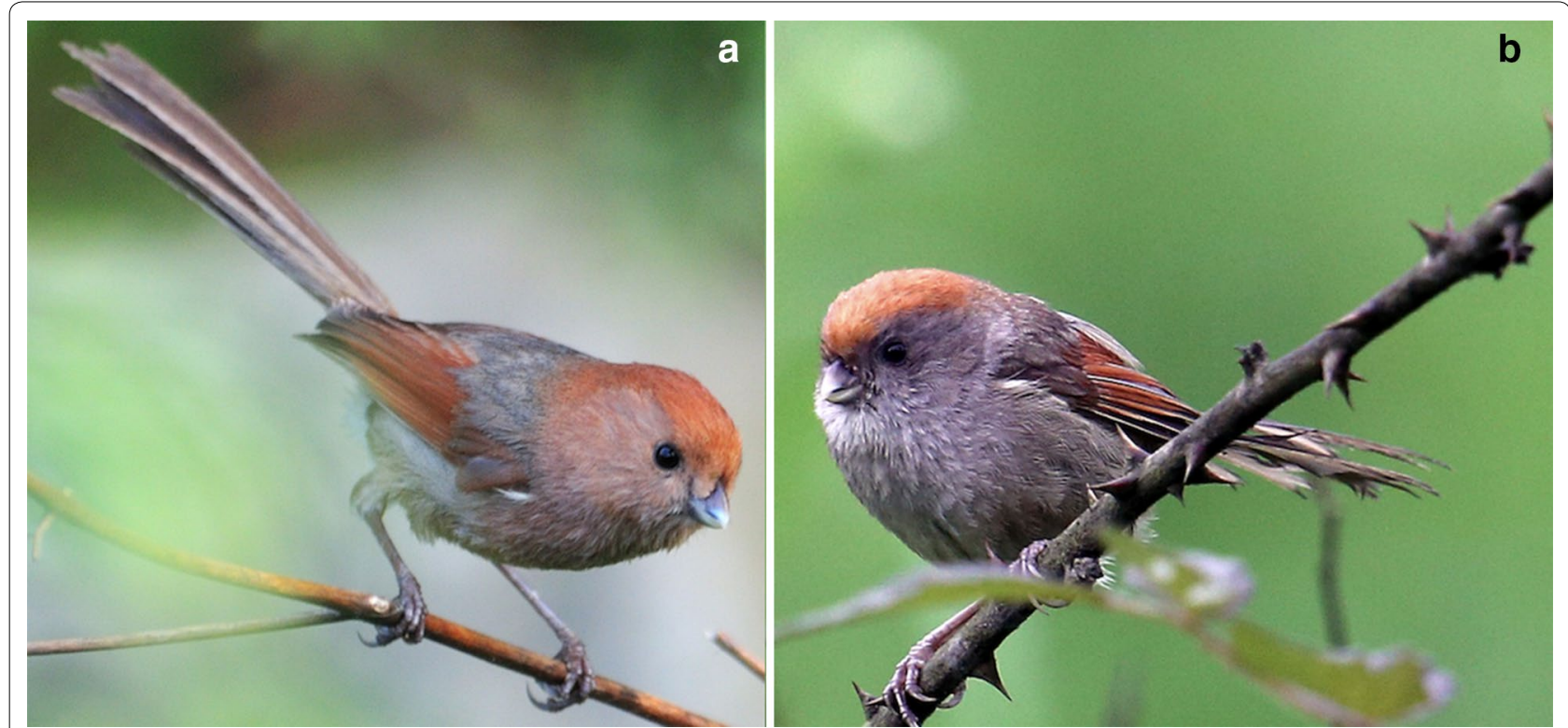

Fig. 1 The Vinous-throated Parrotbill (Paradoxornis webbianus) (a; photo by Naxun Zhao) and Ashy-throated Parrotbill (P. alphonsianus) (b; photo by Bruce Lyon) 


\section{Methods}

\section{Sampling and measurements}

Three geographic populations of Vinous-throated Parrotbills and one population of Ashy-throated Parrotbills were sampled (Fig. 2). The sampling sites include Guizhou, Jiangxi, and Hebei provinces, which represent populations located in southwestern, central and northern China. The Vinous-throated Parrotbill is distributed in all three areas, whilst the Ashy-throated Parrotbill only occurs in a limited area in southwestern China. They are both residents and the distribution ranges of these two parrotbills overlap in southwestern China (Fig. 2).

We set up mist nests from April to July 2016 in shrub, which is the classical habitat for both species of parrotbills, then measured head length, head width, head height, commissural width and tomial length to the nearest $0.01 \mathrm{~mm}$ for calculating head size and bill size by using a digital caliper, body mass to the nearest $0.01 \mathrm{~g}$ with a digital scale and bite force to the nearest $0.01 \mathrm{~N}$ with a micro-signal collector (NBIT-DUD-2404A, NBIT Inc., Nanjing, China) with a sensor probe (S2-200NHL-001). For each individual three values of bite force were measured, and maximal bite force was used to represent bite force (Anderson et al. 2008). Values of head length were obtained by measuring the length from the tip of the beak to the back of the head and then subtracting beak length. Head width was measured as the maximum value at the widest point at the back of the head whilst head height was measured as the maximum value from the top of the head to the bottom behind the jaw. Finally, head size was estimated as the product of these three dimensions and $4 / 3 \pi$ to obtain the volume of a spheroid. For bill size, we calculated the grasp index as the product of commissural width and tomial length (Yang et al. 2015). Tomial length was determined from the commissural point at the corner of the mouth whilst the commissural width was the distance between the commissural points (Rohwer and Spaw 1988).

\section{Statistical analyses}

Generalized linear mixed model (GLMM) with a nested structure of populations nested within species was used to investigate the effect of species and the interaction between species and populations (species $\times$ populations) on head size or maximal bite force by controlling for body mass and sampling date. For the statistics of maximal bite force, bill size was also included as a control variable. Pearson correlation was used to test the relationship between head size and body mass, maximal bite force and body mass, or maximal bite force and head size. For the correlation between maximal bite force and head size, body mass was included as a control variable. Multiple comparisons among values of head size or maximal bite force of the four sampled parrotbill populations was conducted by using the method of Fisher's least significant difference (LSD). All values are presented as mean \pm SD. All statistics were performed in IBM SPSS 20.0 for Windows (IBM Inc., USA).

\section{Results}

In total 94 individual parrotbills were sampled, with similar sample sizes among different populations (Table 1). Head size was positively correlated with bill size ( $r=0.528, \mathrm{df}=94, p<0.001$, Pearson correlation). Head size differed significantly among populations $(F=8.53$, $\mathrm{df}=3, p<0.001$, ANOVA), in which the Guizhou population of Vinous-throated Parrotbill had the largest value $\left(2.06 \pm 0.19 \mathrm{~cm}^{3}\right)$ whilst the Ashy-throated Parrotbill had the smallest value $\left(1.57 \pm 0.15 \mathrm{~cm}^{3}\right)$. Bill size and head size of the Guizhou population of Vinous-throated Parrotbill was larger than that of the other populations and Ashy-throated Parrotbills $(p<0.001$ for all, LSD test; Table 1; Fig. 3), while no statistical differences were detected among the other populations (Tables 1,2).

For maximal bite force, both Ashy-throated Parrotbills and the Guizhou population of Vinous-throated Parrotbills were the smallest with no statistically significant differences $(9.58 \pm 3.36 \mathrm{~N}$ vs. $9.49 \pm 2.91 \mathrm{~N}, p=0.93$, LSD test). However, both were significantly smaller than Jiangxi and Hebei populations of Vinous-throated Parrotbills (Tables 1, 2; Fig. 3). The maximal bite force also differed significantly between pairs of populations in Vinous-throated Parrotbills (Table 2).

We made GLMMs that control for body mass and sampling date in head size comparison and body mass, sampling date and head size in maximal bite force. The resulting comparisons showed that both species and the interaction between species and populations were significant predictors of head size (species: $F_{1,90}=23.76$, $p<0.001$; species $\times$ populations: $F_{2,90}=71.03, p<0.001$, GLMM). That also applied to maximal bite force (species: $\quad F_{1,90}=23.34, \quad p<0.001 ; \quad$ species $\times$ populations:

Table 1 Descriptive values (mean \pm SD) for Vinousthroated and Ashy-throated parrotbills obtained in this study

\begin{tabular}{|c|c|c|c|c|}
\hline & \multicolumn{3}{|c|}{ Vinous-throated Parrotbill } & \multirow{2}{*}{$\begin{array}{l}\text { Ashy- } \\
\text { throated } \\
\text { Parrotbill } \\
\text { Guizhou }\end{array}$} \\
\hline & Guizhou & Jiangxi & Hebei & \\
\hline Head size $\left(\mathrm{cm}^{3}\right)$ & $2.06 \pm 0.19$ & $1.65 \pm 0.22$ & $1.62 \pm 0.12$ & $1.57 \pm 0.15$ \\
\hline $\begin{array}{l}\text { Maximal bite } \\
\text { force }(N)\end{array}$ & $9.49 \pm 2.91$ & $11.94 \pm 3.53$ & $14.24 \pm 4.80$ & $9.58 \pm 3.36$ \\
\hline Body mass (g) & $9.45 \pm 0.70$ & $8.86 \pm 0.54$ & $9.07 \pm 0.68$ & $8.94 \pm 0.71$ \\
\hline $\begin{array}{r}\text { Bill size }\left(\mathrm{mm}^{2}\right. \\
\text { grasp index) }\end{array}$ & $50.37 \pm 3.98$ & $43.79 \pm 5.34$ & $43.03 \pm 4.75$ & $43.03 \pm 4.75$ \\
\hline Sample size & 25 & 24 & 21 & 24 \\
\hline
\end{tabular}




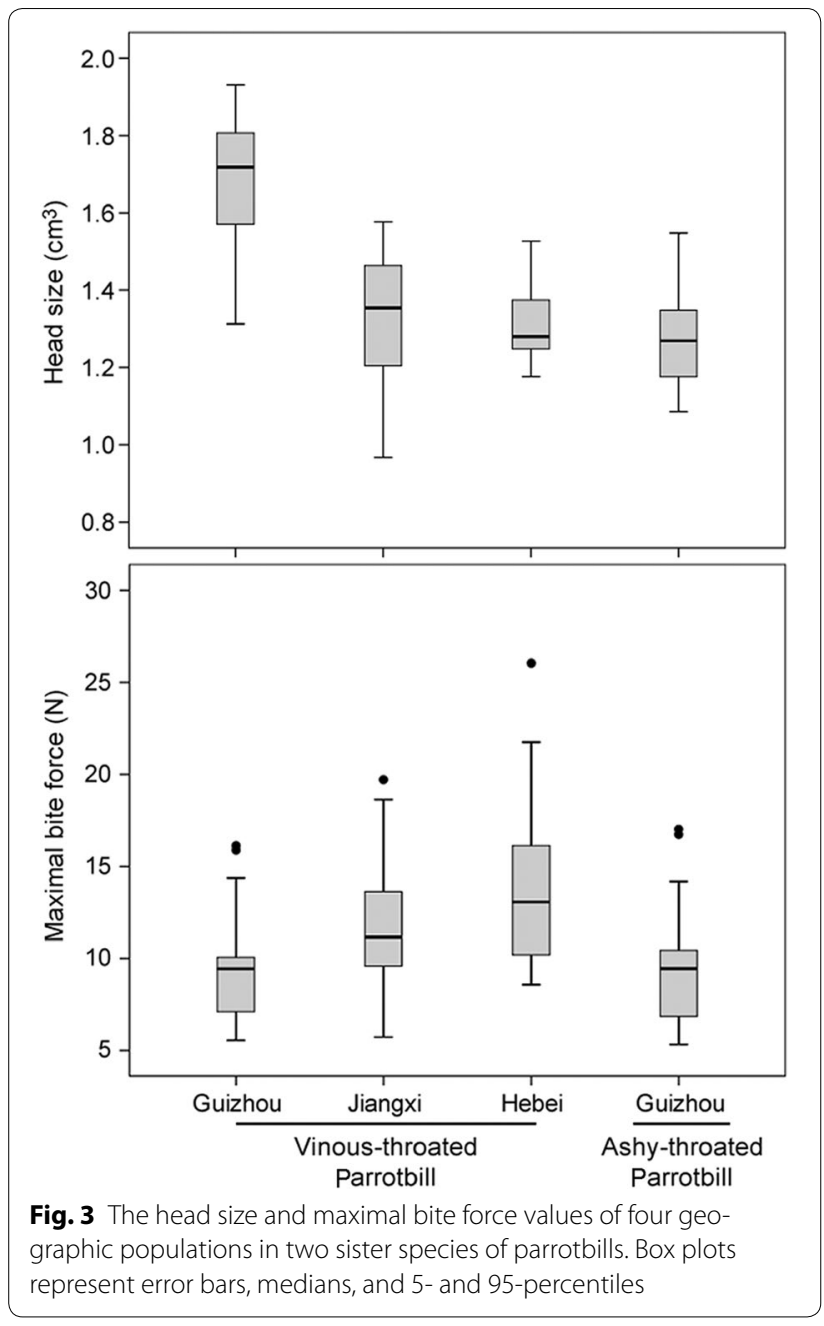

$F_{2,90}=28.55, p<0.001$, GLMM) (Table 3). Finally, head size was positively correlated with body mass $(r=0.304$, $\mathrm{df}=94, p=0.003$; Pearson correlation) whilst maximal bite force was not significantly correlated with either body mass $(r=-0.172, \mathrm{df}=94, p=0.097$, Pearson correlation) or head size after controlling for body mass $(r=-0.131, \mathrm{df}=94, p=0.210$, Pearson correlation).

\section{Discussion}

Numerous studies have supported the idea that animals with larger brain size have more flexible behavior that allows them to deal with challenges of novel environments, and thus perform more efficiently in terms of resource use (Sol and Price 2008). Morelli et al. (2018) also showed that generalist cuckoo species tend to occupy larger distribution ranges than more specialist species. Therefore, it is reasonable to speculate that individuals with larger head size are more flexible in behavior, which is beneficial for colonizing larger areas. Because brain size can be predicted from head size, since they are
Table 2 Multiple comparisons among different populations in two sister species of parrotbills by LSD method

\begin{tabular}{|c|c|c|c|c|}
\hline & \multicolumn{3}{|c|}{ Vinous-throated Parrotbill } & \multirow{2}{*}{$\begin{array}{l}\text { Ashy- } \\
\text { throated } \\
\text { Parrotbill } \\
\text { Guizhou }\end{array}$} \\
\hline & Guizhou & Jiangxi & Hebei & \\
\hline \multicolumn{5}{|l|}{ Head size } \\
\hline \multicolumn{5}{|c|}{ Vinous-throated Parrotbill } \\
\hline Guizhou & - & $* *$ & $* *$ & $* *$ \\
\hline Jiangxi & $* *$ & - & NS & NS \\
\hline Hebei & $* *$ & NS & - & NS \\
\hline \multicolumn{5}{|c|}{ Ashy-throated Parrotbill } \\
\hline Guizhou & $* *$ & NS & NS & - \\
\hline \multicolumn{5}{|c|}{ Maximum bite force } \\
\hline \multicolumn{5}{|c|}{ Vinous-throated Parrotbill } \\
\hline Guizhou & - & * & $* *$ & NS \\
\hline Jiangxi & * & - & * & * \\
\hline Hebei & $* *$ & * & - & $* *$ \\
\hline \multicolumn{5}{|c|}{ Ashy-throated Parrotbill } \\
\hline Guizhou & NS & * & $* *$ & - \\
\hline
\end{tabular}

NS: $p>0.05 ;{ }^{*} 0.01<p<0.05 ;{ }^{* *} p<0.01$

strongly positively correlated (Møller 2010), head size in birds can be used as a representation of brain size. This occurs because birds are constrained in morphology from the extreme costs of flight that put a premium on mass reduction. As predicted, head size of Vinous-throated Parrotbills varies among geographic populations and was significantly larger than that of Ashy-throated Parrotbills. However, the Guizhou populations of Vinous-throated Parrotbills and Ashy-throated Parrotbills had the largest difference in head size. This result is surprising because these two populations are the phylogenetically closest among the two parrotbill species. Thus the contrast in head size should be expected to be the smallest compared to contrasts among other population. One possible explanation may be that selection is intense between the Guizhou populations of the two parrotbills compared to other populations. A recent study showed that interspecific competition strongly influences the evolution of traits involved in resource use (Drury et al. 2018). The two parrotbill species studied here originated from the Himalayan area, where altitude varies considerably. Habitats with distinct altitude can lead to distinct specialization in morphology and life history (Lu et al. 2010; Yang et al. 2012). In Guizhou, Ashy-throated Parrotbills live in the highland while Vinous-throated Parrotbills live in the lowland (Shaner et al. 2015). Furthermore, human settlements are concentrated in the lowland. Therefore, the Vinous-throated Parrotbill that disperses to new habitats (i.e. lowland with human settlement) may face challenges 
Table 3 The results of generalized linear mixed models (GLMM) with nested structure of populations nested in species for testing the predictors (species and the interaction between species and population) of the target measurements (head size or maximal bite force)

\begin{tabular}{lllll}
\hline & $\boldsymbol{F}$ & $\mathbf{d f}_{\mathbf{1}}$ & $\mathbf{d f}_{\mathbf{2}}$ & $\boldsymbol{p}$ \\
\hline Head size* & & & & \\
Corrected model & 61.82 & 3 & 90 & $<0.001$ \\
Species & 23.76 & 1 & 90 & $<0.001$ \\
$\begin{array}{l}\text { Species } \times \text { Population } \\
\text { Maximum bite force** }\end{array}$ & 71.03 & 2 & 90 & $<0.001$ \\
Corrected model & 23.90 & 3 & 90 & $<0.001$ \\
Species & 23.34 & 1 & 90 & $<0.001$ \\
Species $\times$ Population & 28.55 & 2 & 90 & $<0.001$
\end{tabular}

*GLMM was performed by controlling for body mass and sampling date

**GLMM was performed by controlling for body mass, sampling date and bill size

that can be more readily resolved with a larger brain. Previous studies indicated that large brains and associated behavioral flexibility increase speciation rates (Nicolakakis et al. 2003; Ricklefs 2004), and parrotbill individuals that colonize new habitats may favor speciation. However, there are no differences in head size between the Ashy-throated Parrotbill and allopatric populations of Vinous-throated Parrotbill (Jiangxi and Hebei), which provides further evidence for the hypothesis that differences in head size found in the Guizhou populations of the two species are probably the result of local adaptation and are not species-specific.

A recent study revealed fast-evolving ecomorphological variation among populations of Lizards (Podarcis bocagei), where a direct association existed between head morphology and bite performance (Gomes et al. 2018). We investigated differences in bill size and bite force among populations, but the results showed the opposite tendency. The Guizhou population of Ashy-throated Parrotbills is smaller than the Jiangxi and Hebei populations, but not the Guizhou population of Vinous-throated Parrotbills. Variation among populations of Vinous-throated Parrotbills in bite force shows the opposite tendency compared to those for head size and bill size. In other words, the Guizhou populations of the two parrotbill species differed considerably in head size and bill size but not in bite force. Additionally, the tendency of variation in bite force is opposite to those for head size and bill size with populations with larger head size and bill size having weaker bite force. One possible explanation for this pattern is that populations with larger head size have larger bill size as a byproduct. Previous work showed a positive relationship between bill size and acoustic frequencies during song production (Podos 2001; Podos et al. 2004). The upper and lower mandibles of a larger bill may be more difficult to stretch out and draw back by muscles, thus leading to a smaller bite force. This logical assumption is supported because head size was found to be positively correlated with bill size. Finally, variation in bite force among different populations of Vinous-throated Parrotbill may simply reflect geographic variation in food resources, because larger beaks and larger bite force should allow for exploitation of larger and more variable food size (e.g. Lefebvre et al. 1997; Gomes et al. 2018), although this assumption needs further study.

In summary, this study supports the prediction that a larger head leads to more flexible behaviors that may be beneficial for parrotbills to utilize variable resources and thus contribute to their colonization of new habitats. Our study may therefore have implications and perspectives for the role of head size, and by implication brain size, in dispersal and adaptation in birds.

\section{Conclusions}

We showed that there are no differences in head size between the Ashy-throated Parrotbill and allopatric populations of the Vinous-throated Parrotbill, which provides evidence for the hypothesis that differences in head size found in the Guizhou populations of the two sister species are probably the result of local adaptation and are not species-specific. Our study has implications for avian dispersal and adaption related to head size such as diet ecology and vocalizations.

\section{Authors' contributions}

WL and CY conceived and designed the experiment, XR, LM and JZ conducted the experiments and collected field data. APM provided new ideas for this manuscript. CY and XR performed data analyses and wrote the manuscript. WL and APM revised and improved the manuscript. All authors read and approved the final version of the manuscript.

\section{Author details}

${ }^{1}$ Ministry of Education Key Laboratory for Ecology of Tropical Islands, College of Life Sciences, Hainan Normal University, Haikou 571158, China. ${ }^{2}$ Ecologie Systématique Evolution, Université Paris-Sud, CNRS, AgroParisTech, Université Paris-Saclay, 91405 Orsay Cedex, France.

\section{Acknowledgements}

We are grateful to two anonymous reviewers for providing constructive and valuable comments that significantly improved the quality of the manuscript.

\section{Competing interests}

The authors declare that they have no competing interests.

\section{Availability of data and materials}

The datasets used in the present study are available from the corresponding author on reasonable request.

\section{Consent for publication \\ Not applicable.}

\section{Ethics approval and consent to participate}

The experiments comply with the current laws of China in which they were performed. Experimental procedures were in agreement with the Animal 
Research Ethics Committee of Hainan Provincial Education Centre for Ecology and Environment, Hainan Normal University (Permit No. HECEE-2012-003).

\section{Funding}

This work was supported by the National Natural Science Foundation of China (Nos. 31272328, 31472013 and 31772453 to WL, and 31672303 to CY).

Received: 8 June 2017 Accepted: 14 March 2018

Published online: 19 March 2018

\section{References}

Anderson RA, McBrayer LD, Herrel A. Bite force in vertebrates: opportunities and caveats for use of a nonpareil whole-animal performance measure. Biol J Linn Soc. 2008;93:709-20.

Delacour J. Les timaliinèes. L'Oiseau. 1946;16:7-36.

Drury JP, Tobias JA, Burns KJ, Mason NA, Shultz AJ, Morlon H. Contrasting impacts of competition on ecological and social trait evolution in songbirds. PLoS Biol. 2018;16:e2003563.

Garamszegi LZ, Lucas JR. Continental variation in relative hippocampal volume in birds: the phylogenetic extent of the effect and the potential role of winter temperatures. Biol Lett. 2005;1:330-3.

Gomes V, Carretero MA, Kaliontzopoulou A. Run for your life, but bite for your rights? How interactions between natural and sexual selection shape functional morphology across habitats. Sci Nat. 2018:105:9.

Healy SD, Rowe C. A critique of comparative studies of brain size. Proc R Soc B. 2007:274:453-64

Lefebvre L, Whittle P, Lascaris E, Finkelstein A. Feeding innovations and forebrain size in birds. Anim Behav. 1997;53:549-60.

Lu X, Yu T, Liang W, Yang C. Comparative breeding ecology of two whitebellied redstart populations at different altitudes. J Field Ornithol. 2010;81:167-75

Møller AP. Brain size, head size and behaviour of a passerine bird. J Evol Biol. 2010:23:625-35

Morelli F, Benedetti Y, Møller AP, Liang W, Carrascal LM. Cuckoos host range is associated positively with distribution range and negatively with evolutionary uniqueness. J Anim Ecol. 2018. https://doi. org/10.1111/1365-2656.12797.
Nicolakakis N, Sol D, Lefebvre L. Behavioural flexibility predicts species richness in birds, but not extinction risk. Anim Behav. 2003;65:445-52.

Podos J. Correlated evolution of morphology and vocal signal structure in Darwin's finches. Nature. 2001;409:185-8.

Podos J, Southall JA, Marcos R, Rossi-Santos MR. Vocal mechanics in Darwin's finches: correlation of beak gape and song frequency. J Exp Biol. 2004;207:607-19.

Ricklefs RE. Cladogenesis and morphological diversification in passerine birds. Nature. 2004:430:338-41.

Rohwer S, Spaw CD. Evolutionary lag versus bill-size constraints: a comparative study of the acceptance of cowbird eggs by old hosts. Evol Ecol. 1988;2:27-36

Shaner PJL, Tsao TH, Lin RC, Liang W, Yeh CF, Yang XJ, Lei F, Zhou F, Yang C, Hung LM, Hsu YC, Li SH. Climate niche differentiation between two passerines despite ongoing gene flow. J Anim Ecol. 2015;84:829-39.

Sol D, Duncan RP, Blackburn TM, Cassey P, Lefebvre L. Big brains, enhanced cognition, and response of birds to novel environments. Proc Natl Acad Sci USA. 2005;102:5460-5.

Sol D, Lefebvre L. Behavioural flexibility predicts invasion success in birds introduced to New Zealand. Oikos. 2000;90:599-605.

Sol D, Price TD. Brain size and the diversification of body size in birds. Am Nat. 2008;172:170-7.

Sol D, Timmermans S, Lefebvre L. Behavioural flexibility and invasion success in birds. Anim Behav. 2002;63:495-502.

Wyles JS, Kunkel JG, Wilson AC. Birds, behavior and anatomical evolution. Proc Natl Acad Sci USA. 1983:80:4394-7.

Yang C, Liang W, Cai Y, Wu J, Shi S, Antonov A. Variation in russet sparrow (Passer cinnamomeus) breeding biology in relation to small-scale altitudinal differences in China. Zool Sci. 2012:29:419-22.

Yang C, Wang L, Cheng SJ, Hsu YC, Stokke BG, Røskaft E, Moksnes A, Liang W, Møller AP. Deficiency in egg rejection in a host species as a response to the absence of brood parasitism. Behav Ecol. 2015;26:406-15.

Yeung CKL, Lin RC, Lei F, Robson C, Hung LM, Liang W, Zhou F, Han L, Li SH, Yang X. Beyond a morphological paradox: complicated phylogenetic relationships of the parrotbills (Paradoxornithidae, Aves). Mol Phylogenet Evol. 2011;61:192-202.

\section{Submit your next manuscript to BioMed Central and we will help you at every step:}

- We accept pre-submission inquiries

- Our selector tool helps you to find the most relevant journal

- We provide round the clock customer support

- Convenient online submission

- Thorough peer review

- Inclusion in PubMed and all major indexing services

- Maximum visibility for your research

Submit your manuscript at www.biomedcentral.com/submit
(OioMed Central 